\title{
Wilms Tumor-Associated Antisense RNA
}

National Cancer Institute

\section{Source}

National Cancer Institute. Wilms Tumor-Associated Antisense RNA. NCI Thesaurus.

Code C106217.

Wilms tumor-associated antisense RNA ( 23 kb) is encoded by the human WT1-AS gene.

This large non-coding RNA may play a role in the expression of the WT1 gene. 